\title{
Utility of Self-Administered Questionnaires for Identifying Individuals at Risk of COPD in Japan: The OCEAN (Okinawa COPD casE finding AssessmeNt) Study
}

\author{
Kentaro Tamaki ${ }^{1}$ \\ Eishin Sakihara ${ }^{2}$ \\ Hiroaki Miyata ${ }^{3}$ \\ Norimichi Hirahara ${ }^{3}$ \\ Oksana Kirichek ${ }^{4}$ \\ Ryosuke Tawara $\mathbb{1 D}^{5}$ \\ Shoko Akiyama $\mathbb{1}^{5}$ \\ Masayuki Katsumata ${ }^{5}$ \\ Mei Haruya ${ }^{6}$ \\ Takeo Ishii ${ }^{7}$ \\ Edgar $\mathrm{P}$ Simard ${ }^{8}$ \\ Bruce E Miller (D) 8 \\ Ruth Tal-Singer ${ }^{8}$ \\ Toshihiko Kaise $\mathbb{D}^{5}$ \\ 'Department of Breast Surgery, \\ Nahanishi Clinic, Okinawa, Japan; \\ ${ }^{2}$ Lifestyle Related Disease Medical \\ Center, Naha Medical Association, \\ Okinawa, Japan; ${ }^{3}$ Health Policy and \\ Management, School of Medicine, Keio \\ University, Tokyo, Japan; ${ }^{4}$ Value Evidence \\ and Outcomes, GSK, Stockley Park, UK \\ 5 Japan Development, GSK, Tokyo, Japan; \\ ${ }^{6}$ Government Affairs and Market Access, \\ GSK, Tokyo, Japan; ${ }^{7}$ Medical Japan, GSK, \\ Tokyo, Japan; ${ }^{8}$ Value Evidence and \\ Outcomes, GSK, Collegeville, PA, USA
}

Correspondence: Toshihiko Kaise Japan Development, GSK, Tokyo, Japan Tel +8I-80-5927-9500

Email toshihiko.kaise@gsk.com
Purpose: A considerable proportion of patients with chronic obstructive pulmonary disease (COPD) remain undiagnosed and untreated even though they may have a burden of respiratory symptoms that impact quality of life. The OCEAN study assessed the ability of screening questionnaires to identify individuals with, or at risk of, COPD by comparing questionnaire outcomes with spirometric measures of lung function.

Methods: This observational study included participants $\geq 40$ years of age presenting for their annual health examination at a single medical center in Okinawa, Japan. Participants completed COPD screening questionnaires (CAPTURE and COPD-Q), the Chronic Airways Assessment Test (CAAT), and general demographic and health-related questionnaires. The performance characteristics of CAPTURE and COPD-Q were compared with spirometrybased airflow limitation by calculating the area under the receiver operating characteristic (ROC-AUC) curve.

Results: A total of 2518 participants were included in the study; $79 \%$ of whom were $<60$ years of age (mean 52.0 years). A total of 52 (2.1\%) participants had airflow limitation defined as forced expiratory volume in 1 second $\left(\mathrm{FEV}_{1}\right)$ /forced vital capacity $(\mathrm{FVC})<0.7$, and $420(16.7 \%)$ participants were classified as Preserved Ratio Impaired Spirometry (PRISm). Among participants with PRISm, 75 (17.9\%) had a CAAT total score $\geq 10$. Airflow limitation and PRISm were more prevalent in current smokers versus past smokers. For the CAPTURE questionnaire, ROC-AUC for screening airflow limitation, PRISm, and PRISm with a CAAT total score $\geq 10$ were $0.59,0.55$, and 0.69 , respectively; for COPD-Q, these three clinical features were $0.67,0.58$ and 0.68 , respectively.

Conclusion: This study demonstrated that CAPTURE and COPD-Q appear to be effective screening tools for identifying symptomatic individuals with undiagnosed, or at risk of developing COPD in adults $\geq 40$ years of age in Okinawa. Furthermore, early diagnosis and management of PRISm is important to improve future outcomes and the societal burden of disease.

Keywords: COPD, CAAT, COPD-Q, Japan, PRISm, CAPTURE

\section{Plain Language Summary Why Was This Study Done?}

- Many people with chronic obstructive pulmonary disease (COPD) remain undiagnosed and untreated. This can be problematic because, untreated, 
COPD can adversely affect a patient's overall health, daily life, and well-being, which could contribute to increased healthcare use and costs.

- The aim of the OCEAN (Okinawa COPD casefinding Assessment) study was to improve understanding of which patients may have undiagnosed COPD or be at risk of developing COPD.

\section{What Did the Researchers Do/Find?}

- Researchers tested COPD screening questionnaires, COPD Assessment in Primary Care to Identify Undiagnosed Respiratory Disease and Exacerbation Risk (CAPTURE) and COPD screening questionnaire (COPD-Q), to determine how well the questionnaires were able to identify patients with COPD, or those at risk of developing COPD.

- How well the questionnaires worked was assessed by comparing participants' answers to their lung function (measured using spirometry).

- The study found that the CAPTURE and COPD-Q questionnaires were able to effectively identify patients with undiagnosed COPD, and those at risk of developing COPD in adults $\geq 40$ years of age in Okinawa.

\section{What Do These Results Mean?}

- Results from the OCEAN study suggest screening questionnaires may help to increase awareness of COPD and the risk of COPD in Japan. Furthermore, screening questionnaires could help with COPD diagnosis across all age groups, and may also help diagnose people earlier, helping patients and healthcare teams to manage COPD more effectively.

\section{Introduction}

Chronic obstructive pulmonary disease (COPD) is associated with significant morbidity and mortality and is expected to remain a leading cause of death worldwide. ${ }^{1-4}$ COPD prevalence is increasing, especially as a result of population aging. Factors affecting prevalence include age (a large proportion of those diagnosed with the disease are $\geq 40$ years) and smoking status (COPD diagnosis is higher in those who smoke). ${ }^{1}$ The prevalence of COPD in Japan is similar to that in Western countries ${ }^{5}$ and the disease is associated with a significant socioeconomic burden. ${ }^{6}$ However, reported rates of COPD exacerbations are lower in Japan when compared with other countries, with various factors including differences in diagnostic approaches and underreporting of exacerbations hypothesized as contributing to this disparity. ${ }^{7}$ A recent study identified a unique profile of COPD mortality in Japan: death from cardiovascular disease was observed less frequently than has been reported among Western countries and a higher proportion of lung cancer-related death was seen in younger Japanese patients $(<64$ years). ${ }^{8-10} \mathrm{COPD}$ is a known risk factor for lung cancer, therefore early COPD screening strategies may benefit mortality by helping physicians to screen for lung cancer and thus lowering the proportion of lung cancer-related deaths in Japan. ${ }^{8,11}$

The substantial clinical and economic burden associated with COPD is of increasing concern. When left untreated, COPD leads to loss of functional status, which contributes to increased healthcare utilization and costs. ${ }^{12-14}$ Despite the potential to reduce this burden through early diagnosis and treatment, studies indicate that many patients with COPD remain undiagnosed and untreated. ${ }^{15-17}$ In Japan, COPD is an important driver of impairment of health-related quality of life, work, and activity; however, data from one study suggest that only $9.4 \%$ of participants with airflow limitation had been previously diagnosed with COPD. ${ }^{6,15}$ The opportunity to reduce the risk of costly exacerbations is lost when initiation of treatment is delayed until individuals with COPD are at a more advanced disease stage. Well-designed and cost-effective screening tools are therefore needed to enable early identification of patients with COPD and individuals at risk of developing the disease in the primary care setting. Spirometry testing during periodic health examinations may be effective in the early identification of patients with COPD, but this approach may not be costeffective and may not be effective in those without symptoms. ${ }^{18,19}$ An alternative two-step approach would be to screen participants at risk of COPD using questionnaires, and then have their COPD diagnosis confirmed by spirometry testing. ${ }^{18}$

Preserved Ratio Impaired Spirometry (PRISm) is an airflow limitation category that cannot be classified as either normal lung function or COPD using the spirometry-based GOLD definition. ${ }^{20-24}$ PRISm is defined as a reduced forced expiratory volume in 1 second $\left(\mathrm{FEV}_{1}\right.$ $<80 \%$ predicted) in the setting of a preserved $\mathrm{FEV}_{1} /$ forced vital capacity (FVC) ratio $(\geq 0.7),{ }^{20,21,23,25}$ and may potentially represent an "intermediate" category of disease whose phenotype is closer to COPD than that of the 
general population with normal spirometry. ${ }^{23}$ A limited number of studies have investigated PRISm, including the COPDGene study, ${ }^{21,22}$ the SPIROMICS study, ${ }^{26}$ and more recently a general population cohort study in Rotterdam, ${ }^{20}$ but to date PRISm has not been evaluated in a Japanese population. Although PRISm has not been well studied, individuals with PRISm likely represent a group at risk of developing COPD and of increased mortality who could benefit from early diagnosis, careful monitoring, and education about options for better disease management (eg, the cessation of smoking). ${ }^{27}$

As mentioned previously, alternative screening approaches may be beneficial, including screening participants at risk of COPD using questionnaires, followed by confirmation of COPD diagnosis by spirometry testing. ${ }^{19}$ The OCEAN (Okinawa COPD case-finding Assessment) study assessed the ability of the COPD screening questionnaires COPD Assessment in Primary Care to Identify Undiagnosed Respiratory Disease and Exacerbation Risk $(\mathrm{CAPTURE})^{28}$ and COPD questionnaire (COPD-Q) ${ }^{29}$ to identify individuals with, or at risk of, COPD by comparing the questionnaire findings/outcomes with standard spirometry measures of lung function. The OCEAN study is also the first evaluation of PRISm in a working age, general Japanese population.

\section{Materials and Methods Study Design}

The OCEAN study (GSK-sponsored HO-18-19229/ 209243) was an observational, cross-sectional, questionnaire-based study among participants undergoing a scheduled annual health examination at the LifestyleRelated Disease Medical Center study site in Naha, Okinawa, Japan. The study enrollment period was from September 2018 to July 2019 with study participants sequentially recruited without any pre-specified selection or random sampling.

Participants were asked to complete the CAPTURE and COPD-Q screening questionnaires at the study site on the day of the health check-up. Participants were also asked to complete a modified version of the COPD Assessment Test (CAT) questionnaire (Chronic Airways Assessment Test; CAAT) and the Patient-Reported Outcomes Measurement Information System (PROMIS ${ }^{30}$ - a short form 4 questionnaire). The CAAT questionnaire is equivalent to the CAT questionnaire but with the introductory sentence modified to refer to chronic airway disease rather than COPD; for the purposes of this study, whilst undergoing evaluation, CAAT scores were considered equivalent to CAT scores. Total scores for the PROMIS ${ }^{30}$ questionnaire range from 0 to 20 , with a score of 20 indicating a participant is able to carry out certain tasks without any difficulty. Japanese translations of CAPTURE and CAAT, which were used as part of the NOVELTY study, ${ }^{31}$ were obtained from AstraZeneca and used with permission. Other questions related to pulmonary rehabilitation and weight loss were included to estimate the prevalence of physical activity limitation. A summary of the questionnaires in the English language is provided in Table 1, with full questionnaires available in the Supplementary materials.

Participants underwent a pre-bronchodilator lung function test by spirometry performed by skilled technicians (using the spirometer SP-370 COPD Hyper Plus, Fukuda Sangyo). Spirometry-based airflow limitation was defined as $\mathrm{FEV}_{1} / \mathrm{FVC}<0.7$ by pre-bronchodilator spirometry. PRISm was defined as $\mathrm{FEV}_{1} / \mathrm{FVC} \geq 0.7$ and $\mathrm{FEV}_{1}<80 \%$ predicted. The severity of airflow limitation in COPD was further evaluated on a 4-grade scale adapted from the GOLD guidance document. ${ }^{32}$ Using this scale, Grade 1 (mild) was defined as \% predicted $\mathrm{FEV}_{1} \geq 80 \%$; Grade 2 (moderate) was defined as $\%$ predicted $\mathrm{FEV}_{1} \geq 50-79 \%$; Grade 3 (severe) was defined as \% predicted $\mathrm{FEV}_{1} \geq 30$-$49 \%$; and Grade 4 (very severe) was defined as \% predicted $\mathrm{FEV}_{1}<30 \%$.

\section{Ethical Considerations}

This study was conducted in accordance with the Declaration of Helsinki. All participants provided written informed consent before data collection began. The study protocol was approved by the ethics committee of Nahanishi Clinic (Number NNCEC2018004).

\section{Study Population}

Participants eligible for inclusion were males and females $\geq 40$ years of age who attended the study site for their routine annual health examination. All potential participants were invited to complete the questionnaires (Table 1) after providing informed consent during the study enrollment period. A projected sample size of 2500 was determined as being large enough to provide reasonable precision for evaluation of the screening questionnaires. Sample size for the ROC analysis was calculated by using an estimate of AUC 0.80 , a precision of the AUC estimate of 0.05 , and a negative-to-positive 
Table I Questionnaires Used During the OCEAN Study

\begin{tabular}{|c|c|c|}
\hline Questionnaire & Description & Scoring \\
\hline CAPTURE $^{28}$ & $\begin{array}{l}\text { A } 5 \text {-item screening questionnaire used internationally for } \\
\text { screening patients with COPD who are symptomatic or at risk } \\
\text { for COPD exacerbations } \\
\text { Questions assess presence/absence of symptoms (breathing } \\
\text { problems and tiring easily), risk exposures, and recent history of } \\
\text { acute respiratory illnesses }\end{array}$ & $\begin{array}{l}\text { Scores range from } 0 \text { ("no" to all } 5 \text { questions) to } 6 \text { ("yes" to } \\
\text { all questions and at least two respiratory events during the } \\
\text { past year) }\end{array}$ \\
\hline COPD-Q ${ }^{29}$ & $\begin{array}{l}\text { A 5-item screening questionnaire used in Japan for early } \\
\text { detection of COPD in the general Japanese population } \\
\text { Questions assess age presence/absence of symptoms (coughing } \\
\text { phlegm, breathing problems, wheezing) and history of smoking }\end{array}$ & $\begin{array}{l}\text { Scores range from } 0 \text { to } 10 \text { with higher scores indicating } \\
\text { poorer COPD health status }\end{array}$ \\
\hline $\mathrm{CAAT}^{31}$ & $\begin{array}{l}\text { An 8-item questionnaire, which is a modified version of the } \\
\text { COPD Assessment Test (CAT) }{ }^{46,47} \text { with an adaptation of } \\
\text { introductory sentence referring to "chronic airway disease" } \\
\text { instead of COPD } \\
\text { This patient-completed questionnaire covers symptoms such as } \\
\text { cough, phlegm, chest tightness and breathlessness, and disease } \\
\text { impacts including physical activity, confidence, sleep and energy }\end{array}$ & $\begin{array}{l}\text { Scores range from } 0 \text { to } 40 \text {, with higher scores indicating } \\
\text { a poorer chronic airway disease health status }\end{array}$ \\
\hline $\begin{array}{l}\text { PROMIS }{ }^{30,34} \\
\text { Short Form } 4 a\end{array}$ & A 4-item questionnaire for assessing physical function & $\begin{array}{l}\text { Scores range from } 4 \text { to } 20 \text {, with lower scores indicating } \\
\text { poorer physical function }\end{array}$ \\
\hline $\begin{array}{l}\text { Study-specific } \\
\text { questionnaire }\end{array}$ & $\begin{array}{l}\text { A self-administered questionnaire that asked additional questions } \\
\text { related to respiratory disease history and self-reported history of } \\
\text { respiratory diseases, including COPD and asthma diagnoses } \\
\text { (including childhood asthma), symptoms of chronic bronchitis, } \\
\text { smoking history, and history of pulmonary rehabilitation }\end{array}$ & Scores not assessed \\
\hline $\begin{array}{l}\text { A health exam } \\
\text { questionnaire }\end{array}$ & $\begin{array}{l}\text { A questionnaire that was prepared by the study site and used to } \\
\text { collect data as part of the Annual Health Examination Data } \\
\text { collected included demographic information, current medication, } \\
\text { medical history, physical activity, dietary habits, and } \\
\text { anthropometric measures }\end{array}$ & Scores not assessed \\
\hline
\end{tabular}

Abbreviations: CAAT, Chronic Airways Assessment Test; CAPTURE, COPD Assessment in Primary Care to Identify Undiagnosed Respiratory Disease and Exacerbation Risk; COPD, chronic obstructive pulmonary disease; COPD-Q, COPD screening questionnaire; PROMIS, Patient-Reported Outcomes Measurement Information System.

ratio (kappa) for the questionnaire of 2 or 3 , giving a sample size of 1137 (if kappa =2) or 1432 (if kappa $=3$ ). Individuals were excluded from the study if they were judged as inappropriate to participate by the investigator. Pre-existing conditions that could exclude a participant from spirometry testing included (but were not limited to): eye surgery in the last 3 months, chest/ abdominal surgery in the last 3 months, and stroke or heart attack in the last 3 months.

\section{Study Endpoints}

The primary endpoint of the OCEAN study was to assess the ability of the CAPTURE and COPD-Q questionnaires to identify individuals with, or at risk of, COPD. Secondary endpoints included the distribution of responses to CAPTURE, COPD$\mathrm{Q}$, and CAAT and an evaluation of characteristics of participants with airflow limitation, with PRISm, and without airflow limitation or PRISm. A further exploratory endpoint was the prevalence of physical limitations among participants as estimated by the PROMIS Short Form 4a questionnaire.

\section{Study Questionnaires}

All questionnaires were provided to patients in Japanese. COPD-Q was developed in Japan and both COPD-Q and CAT have previously been validated in Japanese. ${ }^{29,33}$ The English versions of PROMIS and CAPTURE have been previously validated, ${ }^{28,34}$ and Japanese translation of the PROMIS Short Form v2.0 Physical Function 4a questionnaires has been 
carried out by the developer. Furthermore, the Japanese versions of the CAAT and CAPTURE questionnaires have been used in the NOVELTY study. ${ }^{31}$ The screening properties of the questionnaires were assessed by calculating their sensitivity (the ability to correctly identify those with the disease by calculating those above and below the threshold of total score for each questionnaire), specificity (ability to identify those without the disease), positive predictive value (probability that participants with a positive screening test truly have the disease), and negative predictive value (probability that participants with a negative screening test truly do not have the disease). Accuracy was calculated as the sum of true positives and true negatives divided by the total number of responses.

\section{Statistical Analyses}

This was a descriptive study, and therefore no specific statistical tests were specified a priori.

The performance properties of each questionnaire were compared with spirometry-based airflow limitation by calculating area under the curve (AUC) of the receiver operating characteristic (ROC) curve.

The ROC curve was based on a logistic regression-based approach, whereby the COPD status was modelled using the responses to the CAPTURE and COPD-Q questionnaires. The dependent variable was spirometry-based airflow limitation $(\mathrm{Y} / \mathrm{N})$, PRISm $(\mathrm{Y} / \mathrm{N})$, and PRISm with higher CAAT score $(\mathrm{Y} / \mathrm{N})$. The independent variable in the ROC analysis was multiple sets of "sensitivity and (1-specificity)" corresponding to multiple thresholds of total score (eg, score 1-5 for CAPTURE, score 1-9 for COPD-Q).

\section{Results}

\section{Study Population}

In total 2550 individuals consented to participate in the study; 2518 of these provided evaluable data and 32 individuals were classed as non-evaluable and excluded from the study population (Table 2). The reasons for exclusion were: 15 participants for not meeting the inclusion criteria, 9 for deficiency in the informed consent form, 4 for already participating in the study (the participants had a second health assessment during the study period), 2 for not completing all the necessary tests, 1 for inconsistency in data and 1 for withdrawal of consent. The participant population was relatively young with $79 \%<60$ years of age (mean age 52.0 years). Approximately half (55.1\%) of participants were male, $24.8 \%$ were current smokers, and mean body mass index (BMI) was $24.3 \mathrm{~kg} / \mathrm{m}^{2}$.

\section{Lung Function}

Mean distribution of lung function is summarized in Table 3. Spirometry-based airflow limitation $\left(\mathrm{FEV}_{1} / \mathrm{FVC}<0.7\right)$ was

Table 2 Baseline Characteristics; Demographic and Lifestyle Variables

\begin{tabular}{|c|c|c|c|}
\hline & Male $(n=1387)$ & Female $(n=|| 3 \mid)$ & Overall $(n=25 \mid 8)$ \\
\hline Age, mean (SD), years & $5 I .3(8.5)$ & $52.8(9.2)$ & $52.0(8.8)$ \\
\hline \multicolumn{4}{|l|}{ Age categories, n (\%) } \\
\hline $40-49$ & 691 (49.8) & $503(44.5)$ & II94 (47.4) \\
\hline $50-59$ & $450(32.4)$ & $353(3 \mid .2)$ & 803 (31.9) \\
\hline $60-69$ & $200(14.4)$ & $223(19.7)$ & $423(16.8)$ \\
\hline $70+$ & $46(3.3)$ & $52(4.6)$ & $98(3.9)$ \\
\hline BMI, mean (SD), $\mathrm{kg} / \mathrm{m}^{2}$ & $25.0(3.9)$ & $23.4(4.2)$ & $24.3(4.1)$ \\
\hline \multicolumn{4}{|l|}{ Smoking history, n (\%) } \\
\hline Not reported & 0 & I $(0.1)$ & I (0.0) \\
\hline Never & $402(29.0)$ & $735(65.1)$ & II 37 (45.2) \\
\hline Past & 509 (36.7) & $247(21.8)$ & $756(30.0)$ \\
\hline Current & $476(34.3)$ & $148(13.1)$ & $624(24.8)$ \\
\hline Pack years, mean (SD) & $20.9(15.4)$ & $10.7(10.6)$ & $18.0(14.9)$ \\
\hline \multicolumn{4}{|l|}{ Pack years, n (\%) } \\
\hline 0 (never smoked) & $402(29.0)$ & $736(65.1)$ & II 38 (45.2) \\
\hline$<10$ & $222(16.0)$ & $213(18.8)$ & $435(17.3)$ \\
\hline$\geq 10$ & $763(55.0)$ & $182(16.1)$ & $945(37.5)$ \\
\hline
\end{tabular}

Abbreviations: BMI, body mass index; SD, standard deviation. 
Table 3 Mean (SD) Distribution of Lung Function

\begin{tabular}{|l|c|c|c|}
\hline & $\begin{array}{c}\text { Male } \\
(\mathbf{n}=1387)\end{array}$ & $\begin{array}{c}\text { Female } \\
(\mathbf{n}=1 \text { I 3 I })\end{array}$ & $\begin{array}{c}\text { Overall } \\
(\mathbf{n}=\mathbf{2 5} \text { I 8) }\end{array}$ \\
\hline $\mathrm{FEV}_{1}, \mathrm{~L}$ & $3.03(0.54)$ & $2.12(0.38)$ & $2.62(0.66)$ \\
\hline $\mathrm{FVC}, \mathrm{L}$ & $3.67(0.62)$ & $2.53(0.43)$ & $3.16(0.78)$ \\
\hline $\mathrm{FEV}_{1} / \mathrm{FVC}$ & $0.83(0.06)$ & $0.84(0.06)$ & $0.83(0.06)$ \\
\hline $\begin{array}{l}\text { Percent predicted } \\
\text { normal FEV }, \%\end{array}$ & $87.7(12.1)$ & $94.1(12.4)$ & $90.6(12.7)$ \\
\hline
\end{tabular}

Abbreviations: $\mathrm{FEV}_{\mathrm{l}}$, forced expiratory volume in I second; FVC, forced vital capacity; SD, standard deviation.

observed in 52 (2.1\%) participants (Table 4), 46 of whom had GOLD stage 2/3 airflow limitation. Of participants with airflow limitation, $63.5 \%(33 / 52)$ were $<60$ years of age. A total of $420(16.7 \%)$ participants were classified as PRISm, and of these 75 had a CAAT total score $\geq 10$ and 140 had a CAAT total score $\geq 7$. The prevalence of PRISm was similar across age groups, including $336(80.0 \%)$ participants who were $<60$ years of age. Both airflow limitation and PRISm were more prevalent among current smokers.

\section{Responses to Questionnaires}

Almost all participants ( $>99 \%$ ) completed the CAPTURE, COPD-Q, CAAT, and PROMIS questionnaires, while fewer completed study-specific (95.6\%) and health examination (76.6\%) questionnaires. Median total score for each questionnaire is summarized in Table 5. Median (interquartile range) total score for CAAT, CAPTURE, and COPD-Q and PROMIS questionnaires was 4.0 (1.0-7.0), 0.0 (0.0-1.0), 2.0 (1.0-3.0), and $20.0(20.0-20.0)$, respectively.

\section{Screening Questionnaire Performance}

Performance indices including sensitivity and specificity for screening various clinical features using CAPTURE and COPD-Q at different cut-points, and AUC-ROC are shown

Table 4 Prevalence of Impaired Lung Function

\begin{tabular}{|c|c|c|c|c|c|c|c|c|}
\hline & \multicolumn{3}{|c|}{$\mathrm{FEV}_{1} / \mathrm{FVC} \geq 0.7$} & \multicolumn{4}{|c|}{ FEV $/$ FVC $<0.7$ (Airflow Limitation) } & \multirow[t]{2}{*}{ Total N } \\
\hline & $\begin{array}{c}\% \\
\text { Predicted } \\
\text { FEV, }<\mathbf{8 0 \%} \\
\text { (PRISm) }\end{array}$ & $\begin{array}{c}\% \\
\text { Predicted } \\
\text { FEV }_{\mathbf{1}} \geq \mathbf{8 0} \%\end{array}$ & n (\%) & GOLD I & GOLD 2 & GOLD 3 & n (\%) & \\
\hline \multicolumn{9}{|l|}{ Gender } \\
\hline Female, n (\%), years & & & & & & & & \\
\hline $40-49$ & $58(11.5)$ & $435(86.5)$ & $493(98.0)$ & I $(0.2)$ & $8(1.6)$ & I (0.2) & $10(2.0)$ & 503 \\
\hline $50-59$ & $37(10.5)$ & $314(89.0)$ & 351 (99.4) & 0 & $2(0.6)$ & 0 & $2(0.6)$ & 353 \\
\hline $60-69$ & $23(10.3)$ & $194(87.0)$ & $217(97.3)$ & $3(1.4)$ & $3(1.4)$ & 0 & $6(2.7)$ & 223 \\
\hline $70+$ & $6(11.5)$ & $42(80.8)$ & $48(92.3)$ & $\mathrm{I}(\mathrm{I} .9)$ & $3(5.8)$ & 0 & $4(7.7)$ & 52 \\
\hline \multicolumn{9}{|l|}{ Male, $n(\%)$, years } \\
\hline $40-49$ & $|3|(19.0)$ & $546(79.0)$ & $677(98.0)$ & 0 & $13(1.9)$ & I $(0.1)$ & $14(2.0)$ & 691 \\
\hline $50-59$ & $110(24.4)$ & $333(74.0)$ & $443(98.4)$ & 0 & $6(1.3)$ & I $(0.2)$ & $7(1.6)$ & 450 \\
\hline $60-69$ & $46(23.0)$ & 147 (73.5) & $193(96.5)$ & $\mathrm{I}(0.5)$ & $5(2.5)$ & I $(0.5)$ & $7(3.5)$ & 200 \\
\hline $70+$ & $9(19.6)$ & $35(76.1)$ & 44 (95.7) & 0 & I (2.2) & $\mathrm{I}(2.2)$ & $2(4.4)$ & 46 \\
\hline \multicolumn{9}{|l|}{ Both, n (\%), years } \\
\hline $40-49$ & $189(15.8)$ & 981 (82.2) & II 70 (98.0) & $I(0.1)$ & $21(1.8)$ & $2(0.2)$ & $24(2.0)$ & 1194 \\
\hline $50-59$ & I47 (I8.3) & $647(80.6)$ & 794 (98.9) & 0 & $8(1.0)$ & I $(0.1)$ & $9(1.1)$ & 803 \\
\hline $60-69$ & $69(16.3)$ & $34 \mid(80.6)$ & $410(96.9)$ & $4(1.0)$ & $8(1.9)$ & $\mathrm{I}(0.2)$ & $13(3.1)$ & 423 \\
\hline $70+$ & $15(15.3)$ & $77(78.6)$ & $92(93.9)$ & I (I.0) & $4(4.1)$ & I (I.0) & $6(6.1)$ & 98 \\
\hline \multicolumn{9}{|l|}{ Smoking history, n (\%) } \\
\hline$N R$ & 0 & I (100) & $I(100)$ & 0 & 0 & 0 & 0 & 1 \\
\hline Never & $178(15.7)$ & $944(83.0)$ & II 22 (98.7) & $4(0.4)$ & $10(0.9)$ & I $(0.1)$ & $15(1.3)$ & 1137 \\
\hline Past & $109(14.4)$ & 634 (83.9) & $743(98.3)$ & I $(0.1)$ & $9(1.2)$ & $3(0.4)$ & $13(1.7)$ & 756 \\
\hline Current & I33 (21.3) & $467(74.8)$ & $600(96.2)$ & I $(0.2)$ & $22(3.5)$ & I $(0.2)$ & $24(3.9)$ & 624 \\
\hline All & $420(16.7)$ & $2046(8 I .3)$ & 2466 (97.9) & $6(0.2)$ & 41 (I.6) & $5(0.2)$ & $52(2.1)$ & 2518 \\
\hline
\end{tabular}

Abbreviations: $\mathrm{FEV}_{1}$, forced expiratory volume in I second; FVC, forced vital capacity; GOLD, Global Initiative for Chronic Obstructive Lung Disease classification; NR, not reported; PRISm, preserved ratio impaired spirometry. 
Table 5 Median (IQR) Total Score for Each Questionnaire

\begin{tabular}{|l|c|c|c|}
\hline & Male & Female & Overall \\
\hline CAAT total score & $4.0(1.0-7.0)$ & $3.0(1.0-7.0)$ & $4.0(1.0-7.0)$ \\
CAPTURE total score & $0.0(0.0-1.0)$ & $0.0(0.0-1.0)$ & $0.0(0.0-1.0)$ \\
COPD-Q total score & $2.0(1.0-3.0)$ & $2.0(1.0-2.0)$ & $2.0(1.0-3.0)$ \\
PROMIS total score & $20.0(20.0-20.0)$ & $20.0(20.0-20.0)$ & $20.0(20.0-20.0)$ \\
\hline
\end{tabular}

Abbreviations: CAAT, chronic airways assessment test; CAPTURE, COPD Assessment in Primary Care to Identify Undiagnosed Respiratory Disease and Exacerbation Risk; COPD, chronic obstructive pulmonary disease; COPD-Q, COPD screening questionnaire; IQR, interquartile range; PROMIS, Patient-Reported Outcomes Measurement Information System.

in Figures 1 and $2 \mathrm{~A}$ and $\mathrm{B}$, and Supplementary Tables 1 and 2 . CAPTURE total score $\geq 1$ and COPD-Q total score $\geq 2$ provided acceptable sensitivity for COPD screening (Figure $2 \mathrm{~A}$ and B). For CAPTURE, AUC-ROC for screening airflow limitation, PRISm, and PRISm with CAAT total score $\geq 10$ were $0.59,0.55$ and 0.69 , respectively (Figure 1); these same three clinical features were $0.67,0.58$, and 0.68 , respectively for COPD-Q (Figure 1). For CAAT $\geq 10$ without PRISm/airflow limitation AUC-ROC values were 0.66 and 0.58 for CAPTURE and COPD-Q respectively (Supplementary Table 1). For each screening target AUC-ROC values by gender were similar for each questionnaire (Supplementary Table 2). CAPTURE and COPD-Q performed better for combined conditions of impaired lung function with respiratory symptoms (PRISm with CAAT total score $\geq 10$ ). COPD-Q also demonstrated a better performance for airflow limitation.

\section{Discussion}

Improved understanding of the prevalence and characteristics of individuals with impaired lung function may inform strategies to enable early diagnosis and more effective management of COPD. OCEAN was the first largescale study to attempt simultaneous assessment of two screening questionnaires (CAPTURE and COPD-Q) among individuals undergoing their annual health examination in Japan. This study demonstrated that CAPTURE and COPD-Q may be effective tools for screening and identifying symptomatic individuals with undiagnosed COPD, or those at risk of developing COPD, among the general population. CAPTURE and COPD-Q could also be effective tools for screening for the combined condition of impaired lung function with respiratory symptoms (PRISm with CAAT total score $\geq 10$ ). This can be seen
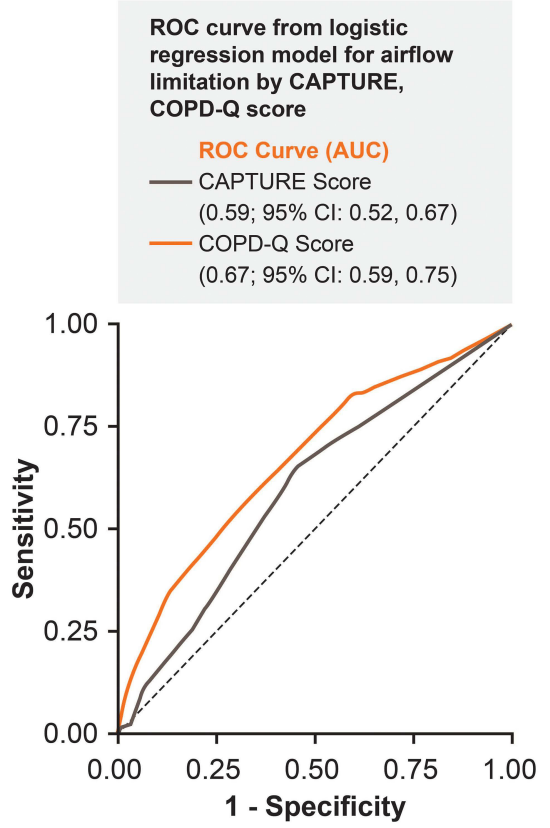

ROC curve from logistic regression model for PRISm by CAPTURE, COPD-Q score ROC Curve (AUC)

- CAPTURE Score $(0.55 ; 95 \% \mathrm{Cl}: 0.52,0.58)$

- COPD-Q Score (0.58; 95\% Cl: 0.55, 0.61)

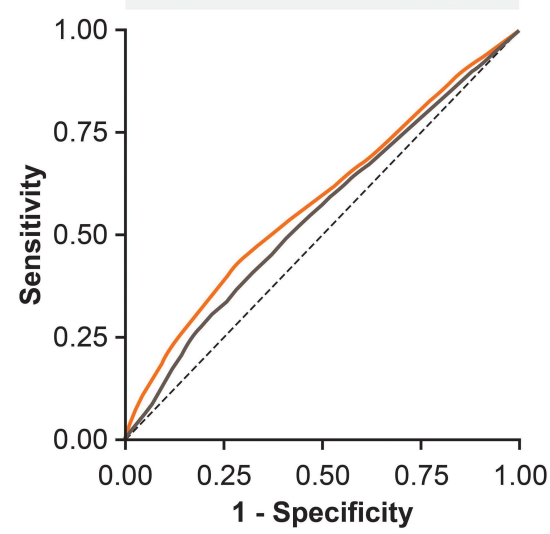

ROC curve from logistic regression model for PRISm/CAAT score $\geq 10$ by CAPTURE, COPD-Q score ROC Curve (AUC)

- CAPTURE Score (0.69; 95\% Cl: 0.62, 0.75)

- COPD-Q Score (0.68; 95\% Cl: 0.62, 0.74)

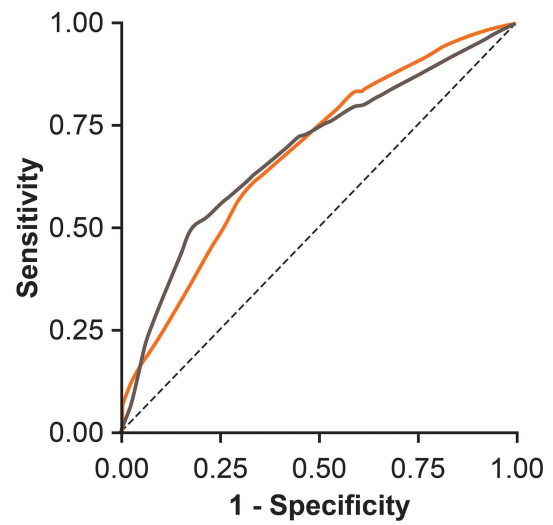

Figure I ROC curve from logistic regression models for airflow limitation, PRISm, and PRISm/CAAT score $\geq 10$ by CAPTURE and COPD-Q total score. Abbreviations: AUC, area under the curve; CAAT, chronic airways assessment test; CAPTURE, COPD Assessment in Primary Care to Identify Undiagnosed Respiratory Disease and Exacerbation Risk; $\mathrm{Cl}$, confidence interval; COPD, chronic obstructive pulmonary disease; COPD-Q, COPD screening questionnaire; PRISm, Preserved Ratio Impaired Spirometry; ROC, receiver operating characteristic. 


\section{A}

CAPTURE

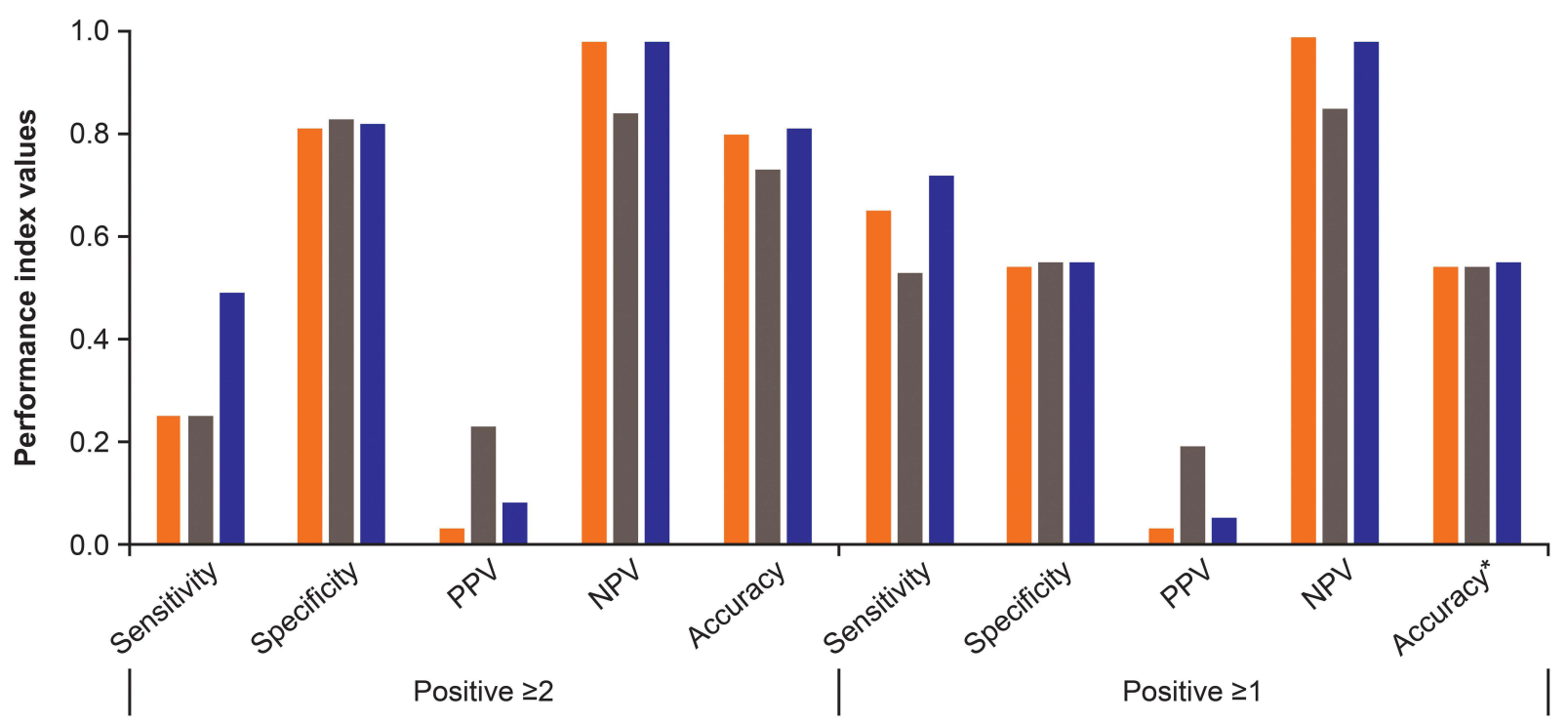

CAPTURE cutoff point

B

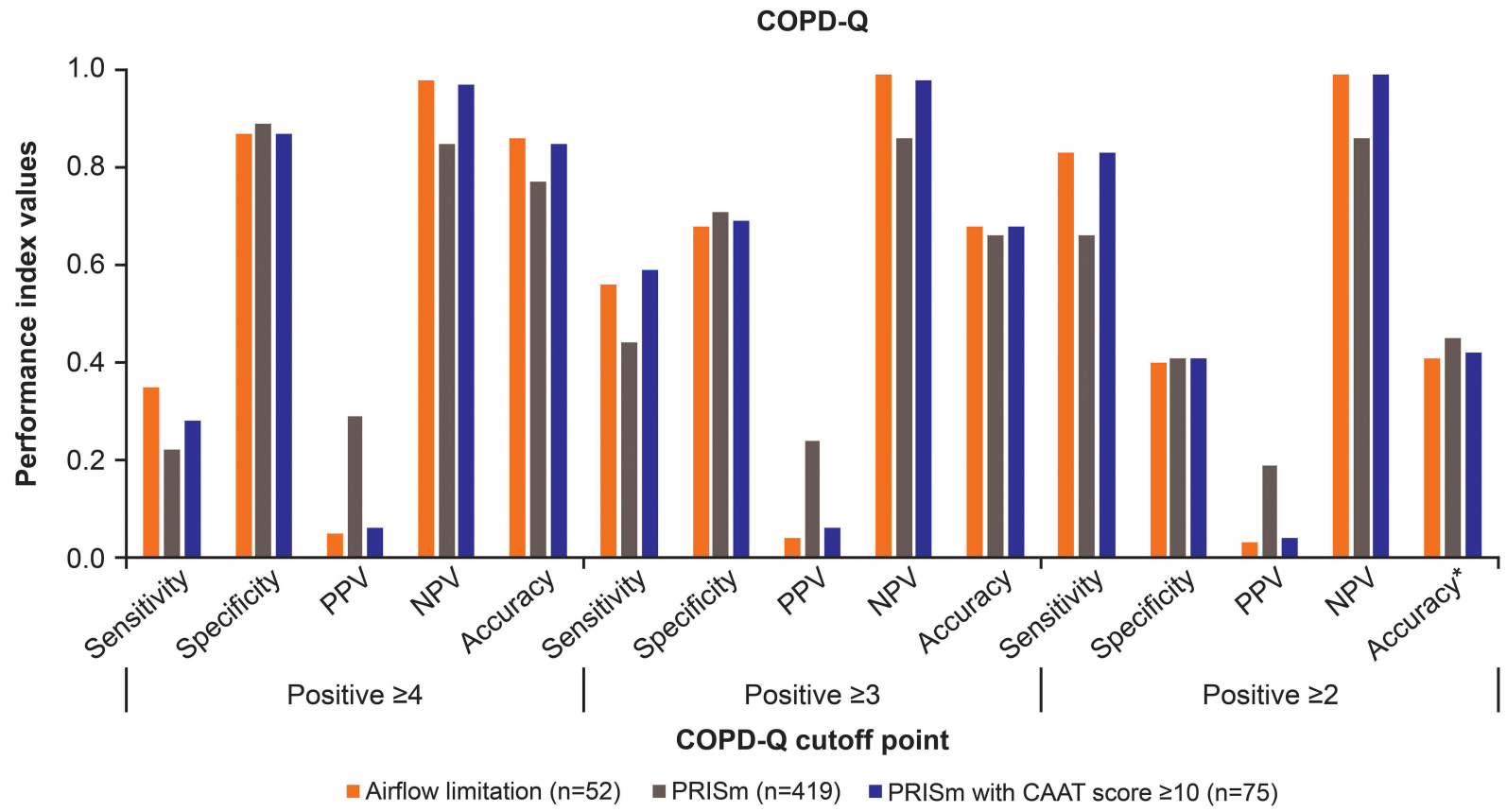

Figure 2 Performance properties of CAPTURE (A) and COPD-Q total score (B). *Accuracy calculated as true positives and true negatives divided by the total number of responses.

Abbreviations: CAPTURE, COPD Assessment in Primary Care to Identify Undiagnosed Respiratory Disease and Exacerbation Risk; CAT, COPD Assessment Test; COPD, chronic obstructive pulmonary disease; COPD-Q, COPD screening questionnaire.

from the sensitivity and specificity values and the AUCROC curves for both questionnaires, with CAPTURE total score $\geq 1$ and COPD-Q total score $\geq 2$ providing acceptable sensitivity for COPD screening.

In the present study, the prevalence of spirometry assessed airflow limitation was $2.1 \%$ and PRISm $16.7 \%$, with the majority of participants in both groups being $<60$ years of age. The majority of participants with PRISm and spirometry assessed airflow limitation were current or past smokers.

Publications have suggested that there is a population of patients that have an $\mathrm{FEV}_{1} / \mathrm{FVC}$ ratio in the normal range but have either respiratory symptoms or lung function abnormalities and could be considered to be in GOLD 
stage 0 or early/pre-COPD. ${ }^{35-37}$ This concept of preCOPD could help identify individuals where COPD is likely to develop but in whom spirometry shows preserved lung function. ${ }^{35}$ This supports questionnaires, such as CAPTURE and COPD-Q, as potentially effective tools for screening for the combined condition of impaired lung function with respiratory symptoms (PRISm with CAAT total score $\geq 10$ ) and for identifying individuals who are pre-COPD without impaired airflow limitation (CAAT $\geq 10$ without PRISm or airflow limitation).

In previous studies conducted in Japan, COPD was commonly diagnosed in the elderly and when the disease was already advanced, ${ }^{15}$ with previous cohort studies reporting the average age of participants with COPD in Japan to be around 70 years. ${ }^{15,38,39}$ Outcomes from this study suggest that there should be an increased awareness of COPD and its risks in Japan, not just among elderly, retired individuals, but also in those who are younger and still working. Raising awareness of COPD in the younger population may allow for earlier diagnosis and intervention, which in turn could benefit COPD progression and clinical outcomes. ${ }^{18}$ PRISm is associated with increased respiratory symptoms, ${ }^{35}$ systemic inflammation, and mortality. ${ }^{20-23}$ A study by Wijnant et al conducted among the general population reported higher mortality in the PRISm group than in the GOLD 1 group. ${ }^{20}$ The finding that $80 \%$ of individuals with PRISm in the current study were $<60$ years of age suggests that early diagnosis and management of PRISm is important to improve future outcomes and the societal burden of disease.

The observed AUC-ROC for the combined condition of impaired lung function with respiratory symptoms (PRISm with CAAT total score $\geq 10$ ) for both CAPTURE and COPD-Q in this OCEAN study (0.7) was lower than that reported in the study that determined CAPTURE to be a viable approach for identifying undiagnosed COPD in the USA in primary care settings $(0.79) .{ }^{25}$ COPD-Q demonstrated a better performance for airflow limitation when compared with CAPTURE. This may be due to the COPD-Q containing questions on age and smoking history, and therefore may be more able to detect airflow limitation; however, this is only a hypothesis at this stage. Other studies that have sought to establish predictive capability of COPD screening questionnaires have reported AUC-ROC values similar to that reported in this study. $^{40-42}$ For example, an AUC-ROC of 0.66 was reported in a study that assessed the predictive value of the Salzburg-COPD screening questionnaire for use in a primary care setting. ${ }^{42}$ Thus, in Japan, the CAPTURE and COPD-Q may be useful to identify symptomatic COPD, but further spirometry assessment would be needed to confirm a diagnosis. Individuals with high scores on these screening questionnaires should undergo spirometry testing, to support early diagnosis, access to preventive care, and/or appropriate COPD treatment.

Some limitations of the OCEAN study should be considered. The study location and population may not be representative of the general population in Japan. In particular, the closed healthcare system used in the study limits extrapolation of the results to other populations. While we included a total of 2518 participants in the study, only 52 had airflow limitation defined as $\mathrm{FEV}_{1}$ $/ \mathrm{FVC}<0.7$, and 420 were classified as PRISm. This may be due to the participants of this study being healthier than the general COPD population in Japan, who are commonly elderly and diagnosed when the disease is already advanced, ${ }^{15,38,39}$ as indicated by the participants' ability to attend their annual health examination; in addition participants' ages were also skewed towards a younger age. These small numbers of COPD cases, and the fact that this study is a single-center study, may limit the validity of the findings. Furthermore, the spirometry in this study was pre-bronchodilator, rather than postbronchodilator, and participants found to have airflow limitation included those with asthma or other respiratory diseases as well as COPD. It has, however, been suggested that pre-bronchodilator spirometry is sufficient and should be performed in the presence of respiratory symptoms, with post-bronchodilator spirometry being performed if evidence of airflow obstruction is present. $^{43-45}$ Finally, there were some inconsistencies in smoking history reporting. The first item of the CAPTURE questionnaire asks about the participants' exposure to a dirty environment, which includes smoking; however, $75.8 \%$ of current smokers and $76.6 \%$ of past smokers answered no to this question. It is therefore not clear in the Japanese translation if smoking is included within this first question, which indicates that refinement of the translated version of the CAPTURE questionnaire to Japanese may be required.

\section{Conclusion}

The OCEAN study demonstrated the ability of both the CAPTURE and COPD-Q questionnaires to effectively identify symptomatic individuals with undiagnosed COPD, or those at risk of developing COPD, among a population of adults $\geq 40$ years of age in Okinawa. This 
could help with increasing awareness to COPD and its risks in Japan. Outcomes from this study also indicate a potential role for the use of screening questionnaires as a way to mitigate challenges associated with identifying COPD across all age groups and could help inform future intervention trials targeting individuals at risk for COPD or those with PRISm who would not be seen in a specialist-care setting. Furthermore, the effective identification of symptomatic individuals with undiagnosed COPD, or those at risk of developing COPD via screening questionnaires may benefit patient management in clinical practice.

\section{Abbreviations}

AUC, area under the curve; BMI, body mass index; CAAT, chronic airways assessment test; CAPTURE, COPD Assessment in Primary Care to Identify Undiagnosed Respiratory Disease and Exacerbation Risk; CAT, COPD Assessment Test; COPD, chronic obstructive pulmonary disease; COPD-Q, COPD screening questionnaire; $\mathrm{FEV}_{1}$, forced expiratory volume in 1 second; FVC, forced vital capacity; OCEAN, Okinawa COPD casE finding AssessmeNt; PRISm, preserved ratio impaired spirometry; PROMIS, Patient-Reported Outcomes Measurement Information System; ROC, receiver operating characteristic; SD, standard deviation.

\section{Data Sharing Statement}

Anonymized individual participant data and study documents can be requested for further research from www. clinicalstudydatarequest.com. The corresponding author had full access to all the data and the final responsibility to submit for publication.

\section{Acknowledgments}

Editorial support in the form of preparation of the first draft based on input from all authors, and collation and incorporation of author feedback to develop subsequent drafts, was provided by Fiona Woodward, PhD, CMPP, and Alexandra Berry at Fishawack Indicia Ltd., UK, part of Fishawack Health, and was funded by GlaxoSmithKline (GSK). Parts of this paper were presented at the American Thoracic Society 2020 Virtual conference as a poster presentation with interim findings. The poster's abstract was published in the American Journal of Respiratory and Critical Care Medicine 2020:201: A5031: https://doi.org/10.1164/ajrccmconference.2020.201.1 MeetingAbstracts.A5031.

\section{Author Contributions}

All authors made a significant contribution to the work reported, whether that is in the conception, study design, execution, acquisition of data, analysis and interpretation, or in all these areas; took part in drafting, revising or critically reviewing the article; gave final approval of the version to be published; have agreed on the journal to which the article has been submitted; and agree to be accountable for all aspects of the work.

\section{Funding}

This study was funded by GSK (Study HO-18-19229/ 209243). The funders of the study had a role in study design, data analysis, data interpretation, and writing of the report.

\section{Disclosure}

Kentaro Tamaki, Eishin Sakihara, Hiroaki Miyata, and Norimichi Hirahara belong to the association/institution that received funding for this study from GSK. Takeo Ishii, Shoko Akiyama, Toshihiko Kaise, Masayuki Katsumata and Ryosuke Tawara are employees of GSK and hold shares in GSK. Mei Haruya, Oksana Kirichek and Edgar P. Simard are former employees of GSK. Bruce E. Miller and Ruth TalSinger are former employees of GSK and hold shares in GSK. Ruth Tal-Singer reports personal fees from Ena Respiratory, Immunomet, Vocalis Health, and Teva. The authors report no other conflicts of interest in this work.

\section{References}

1. Global Initiative for Chronic Obstructive Lung Disease. Global strategy for prevention, diagnosis and management of COPD. 2021. Available from: https://goldcopd.org/gold-reports/. Accessed May 21, 2021.

2. Mathers CD, Loncar D, Samet J. Projections of global mortality and burden of disease from 2002 to 2030. PLoS Med. 2006;3(11):e442. doi:10.1371/journal.pmed.0030442

3. Collaborators GBDCRD. Global, regional, and national deaths, prevalence, disability-adjusted life years, and years lived with disability for chronic obstructive pulmonary disease and asthma, 1990-2015: a systematic analysis for the Global Burden of Disease Study 2015. Lancet Respir Med. 2017;5(9):691-706. doi:10.1016/S2213-2600(17)30293-X

4. World Health Organisation. The top 10 causes of death. 2020. Available from: https://www.who.int/en/news-room/fact-sheets/detail/ the-top-10-causes-of-death. Accessed May 21, 2021.

5. Landis SH, Muellerova H, Mannino DM, et al. Continuing to confront COPD international patient survey: methods, COPD prevalence, and disease burden in 2012-2013. Int J Chron Obstruct Pulmon Dis. 2014;9:597-611. doi:10.2147/COPD.S61854

6. Igarashi A, Fukuchi Y, Hirata K, et al. COPD uncovered: a cross-sectional study to assess the socioeconomic burden of COPD in Japan. Int J Chron Obstruct Pulmon Dis. 2018;13:2629-2641. doi:10.2147/COPD.S167476 
7. Ishii $\mathrm{T}$, Nishimura $\mathrm{M}$, Akimoto $\mathrm{A}$, James $\mathrm{MH}$, Jones $\mathrm{P}$. Understanding low COPD exacerbation rates in Japan: a review and comparison with other countries. Int J Chron Obstruct Pulmon Dis. 2018;13:3459-3471. doi:10.2147/COPD.S165187

8. Makita H, Suzuki M, Konno S, et al. Unique mortality profile in Japanese patients with COPD: an analysis from the hokkaido COPD Cohort Study. Int J Chron Obstruct Pulmon Dis. 2020;15:2081-2090. doi:10.2147/COPD.S264437

9. Shibata $\mathrm{Y}$, Inoue $\mathrm{S}$, Igarashi A, et al. A lower level of forced expiratory volume in 1 second is a risk factor for all-cause and cardiovascular mortality in a Japanese population: the Takahata study. PLoS One. 2013;8(12):e83725. doi:10.1371/journal.pone.0083725

10. Shibata Y, Inoue $S$, Watanabe M. Impact of reduced pulmonary function in the Japanese general population: lessons from the Yamagata-Takahata study. Respir Investig. 2019;57(3):220-226. doi:10.1016/j.resinv.2019.01.005

11. Sekine Y, Katsura H, Koh E, Hiroshima K, Fujisawa T. Early detection of COPD is important for lung cancer surveillance. Eur Respir $J$. 2012;39(5):1230-1240. doi:10.1183/09031936.00126011

12. Price D, Freeman D, Cleland J, Kaplan A, Cerasoli F. Earlier diagnosis and earlier treatment of COPD in primary care. Prim Care Respir J. 2011;20(1):15-22.

13. Foo J, Landis SH, Maskell J, et al. Continuing to confront COPD international patient survey: economic impact of COPD in 12 countries. PLoS One. 2016;11(4):e0152618. doi:10.1371/journal. pone. 0152618

14. Iheanacho I, Zhang S, King D, Rizzo M, Ismaila AS. Economic burden of Chronic Obstructive Pulmonary Disease (COPD): a systematic literature review. Int $J$ Chron Obstruct Pulmon Dis. 2020;15:439-460. doi:10.2147/COPD.S234942

15. Fukuchi Y, Nishimura M, Ichinose M, et al. COPD in Japan: the nippon COPD Epidemiology study. Respirology. 2004;9(4):458-465. doi:10.1111/j.1440-1843.2004.00637.x

16. Omori H, Kaise T, Suzuki T, Hagan G. Prevalence of airflow limitation in subjects undergoing comprehensive health examination in Japan: survey of chronic obstructive pulmonary disease patients epidemiology in Japan. Int $J$ Chron Obstruct Pulmon Dis. 2016;11:873-880. doi:10.2147/COPD.S99935

17. Buist AS, McBurnie MA, Vollmer WM, et al. International variation in the prevalence of COPD (the BOLD Study): a population-based prevalence study. Lancet. 2007;370(9589):741-750. doi:10.1016/ S0140-6736(07)61377-4

18. Kaplan A, Thomas M. Screening for COPD: the gap between logic and evidence. Eur Respir Rev. 2017;26(143):143. doi:10.1183/ 16000617.0113-2016

19. Ruppel GL, Carlin BW, Hart M, Doherty DE. Office spirometry in primary care for the diagnosis and management of COPD: national lung health education program update. Respir Care. 2018;63 (2):242-252. doi:10.4187/respcare.05710

20. Wijnant SRA, De Roos E, Kavousi M, et al. Trajectory and mortality of preserved ratio impaired spirometry: the Rotterdam Study. Eur Respir J. 2020;55(1):1901217. doi:10.1183/13993003.01217-2019

21. Wan ES, Fortis S, Regan EA, et al. Longitudinal phenotypes and mortality in preserved ratio impaired spirometry in the COPDGene study. Am J Respir Crit Care Med. 2018;198(11):1397-1405. doi:10.1164/rccm.201804-0663OC

22. Wan ES, Castaldi PJ, Cho MH, et al. Epidemiology, genetics, and subtyping of preserved ratio impaired spirometry (PRISm) in COPDGene. Respir Res. 2014;15(1):89. doi:10.1186/s12931-014-0089-y

23. Adibi A, Sadatsafavi M. Looking at the COPD spectrum through "PRISm". Eur Respir J. 2020;55(1):1. doi:10.1183/13993003.022172019

24. Global Initiative for Chronic Obstructive Lung Disease. Global strategy for the diagnosis, management, and prevention of COPD. 2020. Available from: https:/goldcopd.org/gold-reports/. Accessed September 10, 2020
25. Vogelmeier CF, Criner GJ, Martinez FJ, et al. Global strategy for the diagnosis, management, and prevention of chronic obstructive lung disease 2017 report. GOLD executive summary. Am J Respir Crit Care Med. 2017;195(5):557-582. doi:10.1164/rccm.201701-0218PP

26. Couper D, LaVange LM, Han M, et al. Design of the subpopulations and intermediate outcomes in COPD Study (SPIROMICS): table 1. Thorax. 2014;69(5):491-494. doi:10.1136/thoraxjnl-2013-203897

27. Strand M, Austin E, Moll M, et al. A risk prediction model for mortality among smokers in the COPDGene ${ }^{\mathbb{B}}$ Study. Chronic Obstr Pulm Dis. 2020;7(4):346-361. doi:10.15326/jcopdf.7.4.2020.0146

28. Martinez FJ, Mannino D, Leidy NK, et al. A new approach for identifying patients with undiagnosed chronic obstructive pulmonary disease. Am J Respir Crit Care Med. 2017;195(6):748-756. doi:10.1164/rccm.201603-0622OC

29. Samukawa T, Matsumoto K, Tsukuya G, et al. Development of a self-scored persistent airflow obstruction screening questionnaire in a general Japanese population: the Hisayama study. Int J Chron Obstruct Pulmon Dis. 2017;12:1469-1481. doi:10.2147/COPD. S130453

30. Schalet BD, Hays RD, Jensen SE, Beaumont JL, Fries JF, Cella D. Validity of PROMIS physical function measured in diverse clinical samples. $J$ Clin Epidemiol. 2016;73:112-118. doi:10.1016/j. jclinepi.2015.08.039

31. Reddel HK, Gerhardsson de Verdier M, Agustí A, et al. Prospective observational study in patients with obstructive lung disease: NOVELTY design. ERJ Open Res. 2019;5(1):1. doi:10.1183/ 23120541.00036-2018

32. Global Initiative for Chronic Obstructive Lung Disease. Global strategy for prevention, diagnosis and management of COPD. 2020. Available from: https://goldcopd.org/gold-reports/. Accessed May 21, 2021.

33. Tsuda T, Suematsu R, Kamohara K, et al. Development of the Japanese version of the COPD assessment test. Respir Investig. 2012;50(2):34-39. doi:10.1016/j.resinv.2012.05.003

34. Cella D, Choi SW, Condon DM, et al. PROMIS( ${ }^{\circledR}$ ) adult health profiles: efficient short-form measures of seven health domains. Value Health. 2019;22(5):537-544. doi:10.1016/j.jval.2019.02.004

35. Han MK, Agusti A, Celli BR, et al. From GOLD 0 to pre-COPD. Am J Respir Crit Care Med. 2021;203(4):414-423. doi:10.1164/ rccm.202008-3328PP

36. Siafakas N, Bizymi N, Mathioudakis A, Corlateanu A. EARLY versus MILD Chronic Obstructive Pulmonary Disease (COPD). Respir Med. 2018;140:127-131. doi:10.1016/j.rmed.2018.06.007

37. Woodruff PG, Barr RG, Bleecker E, et al. Clinical significance of symptoms in smokers with preserved pulmonary function. $N$ Engl J Med. 2016;374(19):1811-1821. doi:10.1056/NEJMoa1505971

38. Miyazaki M, Nakamura H, Chubachi S, et al. Analysis of comorbid factors that increase the COPD assessment test scores. Respir Res. 2014;15(1):13. doi:10.1186/1465-9921-15-13

39. Suzuki M, Makita H, Ito YM, Nagai K, Konno S, Nishimura M. Clinical features and determinants of COPD exacerbation in the Hokkaido COPD cohort study. Eur Respir J. 2014;43 (5):1289-1297. doi:10.1183/09031936.00110213

40. Kotz D, Nelemans P, van Schayck CP, Wesseling GJ. External validation of a COPD diagnostic questionnaire. Eur Respir J. 2008;31 (2):298-303. doi:10.1183/09031936.00074307

41. Marcos PJ, de Molina RM, Casamor R. Risk stratification for COPD diagnosis through an active search strategy in primary care. Int J Chron Obstruct Pulmon Dis. 2016;11:431. doi:10.2147/COPD. S98659

42. Weiss G, Steinacher I, Lamprecht B, et al. Development and validation of the Salzburg COPD-screening questionnaire (SCSQ): a questionnaire development and validation study. NPJ Prim Care Respir Med. 2017;27(1):4. doi:10.1038/s41533-016-0005-7

43. Make BJ. COPD: a new diagnostic paradigm. Chronic Obstr Pulm Dis. 2019;6(5):438-443. doi:10.15326/jcopdf.6.5.2019.0172 
44. Bhatta L, Leivseth L, Carslake D, et al. Comparison of pre- and post-bronchodilator lung function as predictors of mortality: the HUNT Study. Respirology. 2020;25(4):401-409. doi:10.1111/ resp. 13648

45. Mannino DM, Diaz-Guzman E, Buist S. Pre- and post-bronchodilator lung function as predictors of mortality in the Lung Health Study. Respir Res. 2011;12(1):136. doi:10.1186/1465-9921-12-136
46. Jones PW, Harding G, Berry P, Wiklund I, Chen WH, Kline Leidy N. Development and first validation of the COPD assessment test. Eur Respir J. 2009;34(3):648-654. doi:10.1183/09031936.00102509

47. Gupta N, Pinto LM, Morogan A, Bourbeau J. The COPD assessment test: a systematic review. Eur Respir J. 2014;44(4):873-884. doi:10.1183/09031936.00025214

\section{Publish your work in this journal}

The International Journal of COPD is an international, peer-reviewed journal of therapeutics and pharmacology focusing on concise rapid reporting of clinical studies and reviews in COPD. Special focus is given to the pathophysiological processes underlying the disease, intervention programs, patient focused education, and self management protocols. This journal is indexed on PubMed Central, MedLine and CAS. The manuscript management system is completely online and includes a very quick and fair peer-review system, which is all easy to use. Visit http://www.dovepress.com/testimonials.php to read real quotes from published authors. 